\title{
Unarticulated constituents and neo-Gricean pragmatics
}

\author{
Yan Huang \\ The University of Auckland
}

In recent years, the concept of unarticulated constitutes has generated a fierce debate both in the philosophy of language and in linguistic semantics and pragmatics. By unarticulated constituent is meant a propositional (or conceptual) constituent of a sentence that is communicated by the speaker in uttering that sentence, but is not linguistically represented in that uttered sentence. The main aim of this article is to provide a neo-Gricean pragmatic analysis of unarticulated constituents, showing that the current existing mechanism of neo-Gricean pragmatic theory can handle unarticulated constituents in a straightforward and elegant way. Second, I defend the neo-Gricean position that the pragmatic enrichment of unarticulated constituents is nothing but a neo-Gricean, pre-semantic conversational implicature. And third and finally, I briefly evaluate an alternative, formal syntactico-semantic analysis of unarticulated constituents.

Keywords: unarticulated constituent, neo-Gricean pragmatics, pragmatic enrichment, pre-semantic conversational implicature, hidden indexical analysis

This article is dedicated to the memory of John Davey, formerly the Consultant Editor of Linguistics at Oxford University Press

\section{Introduction}

In recent years, the concept of unarticulated constitutes has generated a fierce debate both in the philosophy of language and in linguistic semantics and pragmatics. The focus of the debate is that given that extra-linguistic context affects the truth-conditional, propositional content of a sentence uttered, whether 'all the truth-conditional effects of extra-linguistic context can be traced to logical form' (Stanley 2000: 391), that is, whether they should be accounted for in 
syntactico-semantic or pragmatic terms. According to the syntactico-semantic view, these effects can be traced to a hidden, implicit, or covert semantic indexical, variable, or parameter in the syntax or at the linguistically-decoded logical form of a sentence uttered, and therefore there are no genuine unarticulated constituents (e.g. Stanley 2000, 2002, 2005; Stanley \& Szabó 2000a, b; King \& Stanley 2005; Marti 2006, see also Borg 2005 and Cappelen \& Lepore 2007). By contrast, from a pragmatic perspective, they cannot be so reduced. Rather, there is an unarticulated propositional (or conceptual) constituent of the sentence uttered. The truth-conditional effects of extra-linguistic context are a result of the operation of certain (optional) pragmatic mechanisms (e.g. Recanati 2002, 2007, 2010; Hall 2008; Carston 2010). ${ }^{1}$ Three important issues are involved in the lively debate: (i) are there any genuine unarticulated constituents, (ii) how the semantic content of an unarticulated constituent is recovered, and (iii) if it is pragmatically retrieved, then what is the pragmatic enrichment involved?

The main aim of this article is that given that unarticulated constituents have never received any systematic treatment in neo-Gricean pragmatics, I fill the gap by providing a neo-Gricean pragmatic analysis of them in terms of Horn's $(1984 ; 2004)$ R[elation]- or Levinson's (1987; 2000) I[nformativeness]-principle. Second, following and elaborating on Huang (2005), I defend the neo-Gricean position that the pragmatic enrichment of unarticulated constituents is nothing but a neo-Gricean, pre-semantic conversational implicature. And third and finally, I briefly evaluate an alternative, formal syntactico-semantic analysis of unarticulated constituents (e.g. Stanley 2000, 2002, 2005; Stanley \& Szabó 2000a, b; King \& Stanley 2005; Marti 2006).

The essay is structured as follows. $\$ 2$ is concerned with the question of what an unarticulated constituent is. I begin with a discussion of the linguistic underdeterminacy thesis in $\$ 2.1$. I define unarticulated constituents in $\$ 2.2$. $\$ 2.3$ then presents a list of representative examples of unarticulated constituents. Finally, in $\$ 2.4$, I propose a typology of proposition with unarticulated constituents, following Bach $(1994 ; 2012)$. In $\$ 3$, I comment on an influential, formal syntactico-semantic analysis of unarticulated constituents put forward by Stanley and his colleagues. $\$ 4$ presents a neo-Gricean pragmatic analysis of unarticulated constituents. Finally, $\$ 5$ considers the issue of what the pragmatic enrichment under discussion is.

1. This debate is embedded in the broader, ongoing debate between contextualism and (semantic) minimalism in the philosophy of language. For further discussion, see, for example, Huang (2013a; 2014: 307-311; 2016; see also Bezuidenhout 2017). 


\section{What is an unarticulated constituent?}

\subsection{Linguistic underdeterminacy}

It is widely accepted both in the philosophy of language and in linguistic semantics and pragmatics that there is a (huge) gap between linguistic meaning (roughly, what is said) and speaker meaning (roughly, what a speaker m-intends to mean or communicate). This is embodied in the linguistic underdeterminacy thesis.

(1) Linguistic underdeterminacy thesis

The linguistically encoded meaning radically underdetermines the proposition a speaker expresses when he or she utters that sentence. In other words, the proposition semantically expressed by a sentence a speaker utters can go well beyond what the overt linguistic material in that sentence can literarily mean.

Suppose Rosemary says (2a). On most occasions, the message she m-intends to convey is likely to be something along the line of $(2 \mathrm{~b})$, given an appropriate context. The speaker meaning in (2b) is much more than what can be fully determined by the linguistic meaning in (2a).

(2) a. I have got absolutely nothing to wear.

b. I/the speaker have/has got absolutely nothing [appropriate] to wear [for John's party].

Furthermore, the gap between what is said and what is communicated can be filled only pragmatically by way of context, real-world knowledge, and pragmatic enrichment/inference.

(3) a. the government's safe-sex campaign

b. the government's campaign for safe sex

(4) a. the government's drugs campaign

b. the government's campaign against drugs

The interpretation of (3a) and (4a) relies crucially on our background assumption about what a government would most likely go for or against. This extra-linguistic information is responsible for the two opposing meanings (3b) and (4b).

\subsection{What is an unarticulated constituent?}

The concept of unarticulated constituent was introduced by Perry (1986; 1993; 1998: 9), and somewhat slightly differently by Crimmins (1992: 16). I define unarticulated constitutes as follows. 
(5) An unarticulated constituent

An unarticulated constituent is a constituent of the proposition ${ }^{2}$ of a sentence that is communicated by the speaker when he or she utters that sentence, but is not a constituent of the proposition that is overtly expressed syntactically/ semantically by that uttered sentence. In other words, it is a propositional element that is semantically or truth-conditionally relevant but linguistically or syntactically unrepresented. ${ }^{3,4}$

\subsection{Some representative examples}

A number of representative examples of unarticulated constituents are given in (6)-(34) (see also Bach 2012). The (a) part contains a sentence whose utterance produces an unarticulated constituent. On the other hand, the (b) part lists its proposition with a possible, pragmatically filled unarticulated constituent, relative to a context. As usual, the possible, pragmatically enriched propositional material is put in a bracket.

(6) Atmospheric and other environmental reports

a. It is raining.

b. It is raining [in Beijing]. ${ }^{5}$

snow, drizzle, cold, humid, windy, cloudy, noisy...

(7) Season/time-zone reports

a. It's summer.

b. It's summer [in Australia]. spring, nine o'clock, New Year...

2. I assume that a proposition is structured, and the constituents of a structured proposition consist of items such as objects, properties, and relations (see also e.g. King 2007; Sennet 2011: 422). But I do not share King's (2007) view that a proposition is structured exactly in the way that the sentence is syntactically structured.

3. Defined thus, an unarticulated constituent is a propositional constituent. For a cognitively-oriented theory including a pragmatic one, it can also be defined as a conceptual constituent, as in relevance theory (e.g. Sperber \& Wilson 1995; Hall 2008; Carston 2010).

4. According to Sennet (2011), an unarticulated constituent should be re-defined as an unarticulated occurrence of constituent. His slogan CWR (constituency without representation) is eventually replaced with CNSWR (constituency in a node of a structure without representation).

5. More accurately, (6) may have the logical form 'It is raining $[\mathrm{m}]$ [at $t]$ [in $l]$ ' where $[\mathrm{m}]$ indicates the manner; [at $t$ ], the time/tense; and [in $l$ ], the location. In what follows, I omit $[m]$ and [at $t$ ] for the ease of exposition. 
(8) Expressions with missing objects/complements

a. John hasn't completed.

b. John hasn't completed [his $\mathrm{PhD}$ thesis]. ${ }^{6}$

eat, finish, continue...

(9) a. John is ready.

b. John is ready [for the interview]. late, competent, experienced...

(10) a. John has had enough.

b. John has had enough [to drink].

(11) a. Mary isn't slim enough.

b. Mary isn't slim enough [for a fashion model]. strong enough, tall enough, clever enough...

(12) a. John hasn't washed his face.

b. John hasn't washed his face [this morning].

(13) Sentences with missing domain restrictions Quantifiers

a. Every professor jogs.

b. Every professor [at Auckland University] jogs.

(14) Comparatives

a. Elizabeth is clever.

a. Elizabeth is clever [than Naomi].

(15) Superlatives

a. John is the best student.

b. John is the best student [in his class].

(16) Relative/degree adjectives

a. John is tall.

b. John is tall [for/relative to an average adult Caucasian man]. long, heavy, narrow...

6. The anonymous referee claimed that a Chinese sentence like (i) has two unarticulated constituents, namely, a missing subject and a missing object. But this view is incorrect. Unlike the missing object, the missing subject is not a propositional constituent that is not linguistically indicated. Rather, it is syntactically represented by an empty category (EC) in the classical Chomskyan sense (e.g. Chomsky 1995). Therefore, the missing subject is not an unarticulated constituent defined in this article.

(i) Ø chi le. eat PFV e.g. $(\mathrm{He})$ has eaten.

The same remark applies to other null-subject languages such as Italian, Modern Greek, and Yukaghir. For my arguments against the Chomskyan typology of empty categories including the assumption that a null subject is a pro in Chinese, see e.g. Huang (1992a, b; 1994/2007: 33-44; 2000). 
(17) Absolute adjectives used as loose terms

a. France is hexagonal.

b. France [the region] is [roughly] hexagonal[-shaped]. round, flat, full, raw, pure...

(18) Cardinal number strengthening

a. Yan has two doctorates.

b. Yan has [exactly] two doctorates.

(19) Relational expressions

a. John is a friend.

b. John is a friend [of Nelson Mandela].

fan, local, foreign...

(20) Perspective expressions

a. The hospital is on the right.

b. The hospital is on the right [after you cross that street].

left, behind, horizon...

(21) Terms for response-dependent properties

a. This plant is edible.

b. This plant is edible [for horses].

comfortable, scary, lethal...

(22) Predicates of personal taste

a. Cheese is tasty.

b. Cheese is tasty [to people who like it].

funny, boring, interesting...

(23) Possessive constructions

a. John's book

b. the book [written by] John

(24) Noun-noun compounds

a. a bread knife

b. a knife [used to slice bread]

cf. a kitchen/pocket/steel knife

(25) Adjective-noun combinations

a. a red watermelon

b. a watermelon [that is red inside its flesh]

cf. a red apple/flag/car

(26) Sentences expressing a trivially true proposition

a. Some people are a bit surprised when they found out that I've got a brain. (Catherine McQueen)

b. Some people are a bit surprised when they found out that I've got a [good] brain. 
(27) Distance/time-sentences

a. It took time for Yan to write The Oxford Dictionary of Pragmatics.

b. It took [a long] time for Yan to write The Oxford Dictionary of Pragmatics.

(28) Sentences expressing a patently false proposition

a. You are not going to die.

b. You are not going to die [from this small cut].

(29) Incomplete definite descriptions

a. The desk is covered with pragmatics monographs.

b. The desk [in my study] is covered with pragmatics monographs.

(30) Bridging-cross reference

a. John walked into a music room. The piano was made in the eighteenth century.

b. John walked into a music room. The piano [in the music room John walked into] was made in the eighteenth century.

(31) Deferred reference

a. Dickens is on the top of that shelf.

b. [The novels written by] Dickens are on the top of that shelf.

(32) Conjunction-buttressing

a. John has eaten a lot of oily fish recently and his blood cholesterol level has been lowed.

b. John has eaten a lot of oily fish recently and [as a result] his blood cholesterol level has been lowed.

(33) Mirror maxim

a. John and Mary cleaned the sitting room.

b. John and Mary cleaned the sitting room [together].

(34) Conditional perfection

a. If you let me see the manuscript, I'll make a donation to the library.

b. If [and only if] you let me see the manuscript will I make a donation to the library. ${ }^{7}$

7. I shall not discuss sub-sentential utterances including ellipsis such as (i-iii) in this article.

(i) (Context: Holding a box of chocolates)

From Belgium.

(ii) In the sitting room.

(iii) I will, if you will.

For arguments against the existence of unarticulated constituents based partially on this type of examples, see Vicente \& Groefsema (2013), and for a pragmatic enrichment analysis, see Stainton (2006). See also Huang (2000: 3-5, 131-156) for a discussion of various types of vP-anaphora such as vP-ellipsis, gapping, sluicing, stripping, and null complement anaphora. 
Note that as shown by the (a) of (6-34), syntactically, these sentences/phrases are well-formed. In other words, they do not contain any unarticulated syntactic constituents, and therefore they do not need to be syntactically completed or expanded. Rather, as already mentioned in $\$ 2.2$, it is the propositions semantically expressed by the uttering of these sentences/phrases that contain unarticulated propositional constituents.

\subsection{Two types of proposition with unarticulated constituents}

Following Bach $(1994 ; 2004 ; 2012)$, propositions that contain unarticulated constituents are divided into two types.

Type i. Propositions that need to be completed

In the first place, there is the type of proposition that is exemplified by, for example, the (b) of (8-11) without the pragmatically added propositional ingredients that are put in a bracket. In Bach's view, this type of proposition is incomplete. As a consequence, it cannot be evaluated truth-conditionally. Bach dubbed propositional fragments of this kind propositional radicals or propositional skeletons, which need to be contextually filled or completed to become fully propositional. The pragmatic process of completion will provide extra semantic content to the propositional radicals, resulting in the corresponding minimal but full propositions. The full propositions can then be assigned a truth value.

Type ii. Propositions that need to be expanded

Second, we have the type of proposition that is illustrated by, for instance, the (b) of (6), (7), (12), (16), and (25-34) without the pragmatically supplied propositional elements bracketed. Unlike type (i) propositions, type (ii) propositions are fully, though minimally propositional. But such a proposition falls short of what the speaker has $\mathrm{m}$-intended to mean. Consequently, it needs to be expanded. The pragmatic process of expansion will flesh out the proposition semantically expressed by the sentence uttered and give rise to a richer proposition. This pragmatically enriched proposition will then be in keeping with what the speaker has intentionally meant, thus allowing the assignment of an appropriate truth value to it.

\section{A formal syntactico-semantic account of unarticulated constituents}

Let me now turn to an influential, formal syntactico-semantic account of unarticulated constituents, known as the hidden indexical analysis, advanced by Stanley and his colleagues (e.g. Stanley 2000, 2002, 2005; Stanley \& Szabó 2000a, b; King \& Stanley 
2005, and Marti 2006). The central idea of the analysis is that the extra-linguistic contextual effects on, or pragmatic contributions to, the truth-conditional, propositional content of a sentence uttered should be identified with the syntactic structure of the sentence, and reduced to the treatment of ordinary cases of pure indexicals like I, here, and now in formal semantics. More specifically, the contextual effects or pragmatic contributions involve only the completion (Bach 1994) or saturation (Recanati 2004) of a hidden, implicit, or covert semantic indexical, parameter, or variable in the syntax or at the linguistically-decoded or provided logical form of a sentence uttered, ${ }^{8}$ and the (pragmatic) process is mandatory and bottom-up. In other words, the role played by the Gricean mechanism/context here, unlike in producing a conversational implicature, is 'semantic' in nature. Although some elements of the truth-conditional, propositional content of the sentence uttered may not be phonologically present, they are still articulated in the sense that the need for them to be filled is linguistically/syntactically or semantically called for. Consequently, they are hidden indexicals rather than unarticulated constituents. In other words, according to the hidden indexical analysis, there are no real unarticulated constituents.

One of the main motivations behind postulating a hidden indexical is to provide an analysis of the meaning of (35) in terms of quantifier-variable binding, following the spirit of Partee (1989).

(35) a. Wherever Mary attends a pragmatics conference, it rains.

b. Wherever $(x)$ Mary attends a pragmatics conference, it rains in $x .^{9}$

Since there is a quantifier, namely, wherever in (35a), the quantifier needs an indexical (or variable) to bind it, as in (35b). Extending this 'argument from binding' to cases where there is no quantifier, Stanley (2002) argued for the presence of hidden indexicals or covert variables especially in weather reports (6), sentences with missing domain variables (13), and relative adjectives (16). ${ }^{10}$

8. The notion of hidden indexicals was introduced by Schiffer (1977: 31-36).

9. In Bach's (2012: 163) view, the same analysis does not work for (i).

(i) Whenever John attends a pragmatics conference, it rains.

In this example, the variation in location of raining is understood. There is, however, no suitable quantificational phrase (i.e. wherever) to bind a hidden indexical or covert variable for location to which rain is predicated. But Bach's analysis is challenged by Jo-wang Lin. According to him, the universal quantifier is -ever or an implicit operator in the structure, which may bind both the time variable associated with when and the location variable that lacks an overt linguistic element.

10. See also, for example, Borg (2005) and Cappelen \& Lepore (2007) for an alternative, less syntactically - but more semantically-oriented account within the camp of (semantic) minimalism. 
While the hidden indexical account offers an ingenious formal syntacticosemantic analysis of unarticulated constituents, it suffers from a number of problems. Let me mention just two here. In the first place, as pointed out by Bach (2000); Carston (2002); Recanati (2002), and Cappelen \& Lepore (2007), it is not the case that a weather predicate like rain always needs a location. Sometimes, instead of expressing a location-specific proposition, as is typical in (6), it may express either a location-general (in the terminology of Recanati 2002), or a location-neutral (in the terminology of Cappelen \& Lepore 2007) proposition. This is illustrated in (36-38).

(36) When it rains, water falls from the clouds in drops.

(37) The 'weatherman' example

(Recanati 2002; 2007)

I can imagine a situation in which rain has become extremely rare and important, and rain detectors have been disposed all over the territory (whatever the territory - possibly the whole Earth). In the imagined scenario, each detector triggers an alarm bell in the Monitoring Room when it detects rain. There is a single bell; the location of the triggering detector is indicated by a light on a board in the Monitoring Room. After weeks of total drought, the bell eventually rings in the Monitoring Room. Hearing it, the weatherman on duty in the adjacent room shouts: 'It is raining!' His utterance is true, if it is raining (at the time of utterance) in some place or other (but see Marti 2006: 153 for a re-interpretation of this example).

(38) The 'rain-ache universe' example

(Cappelen \& Lepore 2007: 209-210) This universe differs from ours in four respects: a. Rain is never noticed by humans as wetness - as soon as rain touches any object it evaporates immediately - so there is no need for umbrellas or any other rain-protection instruments. b. Food is not grown, so there is no need for rainfall for that purpose. c. Whenever it rains, however, no matter where it rains, through some poorly understood causal mechanism, it causes headaches in humans. And humans need not be in the vicinity of rain to get a headache. $d$. These headaches can be avoided by wearing yellow hats. In the rain-ache universe, parents are prone to tell their kids things like: 'If it rains, you have to wear a yellow hat.' To avoid these epidemic headaches, humans place rain detectors around the entire globe and put out daily warnings that say things like: It will rain at 2 p.m., so make sure to bring your yellow hats... [I]t seems plausible to assume that those who speak about rain in this universe will do so without any interest whatsoever in the location of rain. The location will never be salient. The only thing they will care about is not where it rains but whether it rains... They will express that by uttering sentences like: I don't care where it rains; I only care whether it rains. ${ }^{11}$

11. Note also Perry's (1986) Z-land example. Z-landers are a community of primitive thinkers imagined by Perry. When they hear a meteorological sentence such as It's raining, they do not 
In (36-38), contra Taylor (2001), the verb rain does not take an argument place for location. Put in a slightly different way, as Carston (2010) pointed out, (36-38) give rise to an existential closure reading, and this existentially closed interpretation is sufficient in these contexts. All this indicates that contrary to Stanley and his colleagues, at least in sentences such as (36-38), there lacks a slot for a hidden indexical or covert variable for location - the alleged implicit counterpart of an overt indexical (see also Bach 2000 for arguments against, and Stanley \& Szabó $2000 \mathrm{~b}$ for a defence of this analysis). As a way to tackle this problem, Marti (2006), a strong supporter of the Stanley analysis suggested that the hidden indexical or covert variable is optional: that is, if and when it does occur in the syntax or at the logical form of a sentence uttered, then there has to be a process for it to be saturated contextually, namely, to be provided with a specific contextual value using 'all the principles of grammar, including Gricean principles' (Marti 2006: 150). But, as pointed out by both Carston $(2002: 204 ; 2010)$ and Recanati (personal communication to Marti 2006), among others, Marti's proposal has an undesirable consequence: it will generate quite a number of distinct logical forms for a single surface form. For instance, if a sentence has four hidden indexicals or covert variables for different constituents such as one for object/complement, one for place, one for time, and finally one for manner, it will have sixteen distinct logical forms, which is both 'widely counter-intuitive and excessively computationally burdensome' (Carston 2010: 236). ${ }^{12}$

Second and more importantly, the account proposed by Stanley and his colleagues does not generalize to all the different cases of context dependency and unarticulated constituents. In their analysis of, for example, sentences with missing domain restrictions (13), following an idea from Westerståhl (1985), Stanley \& Szabó (2000a: 251-252) assume that a common noun such as professor co-habits a node with a contextual indexical or variable. Consequently, (13) has the syntactio-semantic representation in (39).

$$
\left[{ }_{S}\left[{ }_{N P}\left[{ }_{\text {Det }} \text { every }\right]\left[_{N}<\text { professor, } f(i)>\right]\right]\left[_{\mathrm{VP}}\left[\left[_{\mathrm{V}} \text { jogs }\right]\right]\right]\right.
$$

have the conception of when it rains (at a given time), or it usually rains at a particular place, typically where the speaker is. This raises the possibility that in Z-land, It's raining does not contain an unarticulated constitute for location.

12. Jo-wang Lin pointed out to me that for (36), given the hidden indexical analysis, it can have a logical form along the following line:

For all $t, t$ a time, when there exists an $l, l$ a location, it rains at $l$ at $t$, water falls from the clouds in drops.

Since the existential operator is embedded to a universal one, a location-neutral reading is yielded. Consequently, the problem of sixteen distinct logical forms will be avoided. This is also true of (37) and (38). 
The values of $i$ and $f$ are supplied by the relevant context. (Notice that as already mentioned above, the pragmatic process of providing a value for $i$ and $f$ is mandatory and bottom-up.) Consequently, in (13), the set of those who are at Auckland University is intersected with the set of professors to produce the restricted domain for the quantificational phrase every professor, namely, 'at Auckland University', as is represented in the logical form (40) (Bezuidenhout 2017:31).

(40) [Every $x$ : professor $(x) \&$ at (x, Auckland University)] jogs $(x)$

However, as pointed out by Bezuidenhout (2017: 31-32), Stanley \& Szabó's (2000a) analysis is dependent on the technical notion of nominal restriction. It is not clear at all that this method can be extended to sentences in which context-dependency is triggered by parts of speech other than nouns, such as by verbs (8), by adjectives (9), or by sentence connectives (32). To claim that every part of speech in a natural language co-habits a node with a contextual indexical or variable is far-fetched, to say the least

Furthermore, while the Stanley-type analysis may account for unarticulated constituents in type (i) propositions, it does not work for unarticulated constituents in type (ii) propositions. This is because unlike type (i) propositions, which are semantically incomplete or underdetermined, type (ii) propositions are semantically complete, in which case, an unarticulated constituent cannot be linguistically/ syntactically or semantically called for, hence there is no hidden indexical or covert variable that can linguistically trigger an unarticulated constituent.

\section{A neo-Gricean pragmatic analysis of unarticulated constituents}

\subsection{Classic Gricean pragmatics}

On a general Gricean account of meaning and communication, there are two theories: a theory of meaning-n[on]n[atural] and a theory of conversational implicature (e.g. Grice 1975; 1989). In his theory of meaning-NN, Grice emphasized the conceptual relation between natural meaning in the external world and non-natural, linguistic meaning of utterances. He developed a reductive analysis of meaning-NN in terms of the speaker's reflexive intention, the essence of which is that meaning-NN or speaker meaning is a matter of expressing and recognizing intention.

In his theory of conversational implicature, Grice suggested that there is an underlying principle that determines the way in which language is used maximally efficiently and effectively to achieve rational interaction in communication. He called this overarching dictum the co-operative principle and subdivided it into nine maxims of conversation classified into four categories: Quality, Quantity, Relation, and 
Manner. These four categories are taken from the German philosopher Immanuel Kant (Grice 1989: 26). The co-operative principle and its component maxims ensure that in an exchange of conversation, truthfulness, informativeness, relevance, and clarity are aimed at.

(41) Grice's theory of conversational implicature (simplified)

a. The co-operative principle

Be co-operative.

b. The maxims of conversation

Quality: Be truthful.

i. Don't say what is false.

ii. Don't say what lacks evidence.

Quantity:

i. Don't say less than is required.

ii. Don't say more than is required.

Relation: Be relevant.

Manner: Be perspicuous.

i. Avoid obscurity.

ii. Avoid ambiguity.

iii. Be brief.

iv. Be orderly.

Assuming that the co-operative principle and its associated maxims are normally adhered to by both a speaker and the addressee in a conversational interaction, Grice suggested that a conversational implicature - roughly, any meaning or proposition expressed implicitly by a speaker in his or her utterance of a sentence which is meant without being part of what is said in the strict sense ${ }^{13}$ - can arise from either strictly observing or ostentatiously flouting the maxims. In Huang (e.g. 2007, $2014,2015,2017 a)$, I called conversational implicatures that are engendered by way of directly observing the maxims conversational implicatures ${ }_{\mathrm{O}}$, and conversational implicatures that are generated by way of the speaker's deliberately flouting the maxims conversational implicatures F $_{\text {. }}$

A second Gricean dichotomy, independent of the conversational implicature $/$ conversational implicature $\mathrm{F}_{\mathrm{F}}$ one, is between those conversational implicatures which arise without requiring any particular contextual conditions and those which do require such conditions. Grice (1989: 31-38) called the first kind generalized conversational implicatures, and the second kind particularized conversational implicatures.

13. Defined thus, conversational implicature is a component of speaker meaning rather than a pragmatic inference (e.g. Saul 2002; Horn 2004, 2012; Bach 2012). By contrast, Sperber \& Wilson (1995) and Levinson (2000) are still treating conversational implicature as a pragmatic inference. 
Finally, Grice designed a battery of tests to facilitate the identification of conversational implicature. First, defeasibility or cancellability - conversational implicatures can disappear in certain linguistic or non-linguistic contexts. Second, non-detachability - any linguistic expression with the same semantic content tends to carry the same conversational implicature. (A principled exception is those conversational implicatures that arise via the maxim of Manner.) Third, calculability - conversational implicatures can transparently be derived via the co-operative principle and its attendant maxims. Fourth, non-conventionality - conversational implicatures, though dependent on the saying of what is coded, are non-coded in nature. Fifth, reinforceability - conversational implicatures can be made explicit without producing too much sense of redundancy. Sixth, some conversational implicatures may be indeterminate. They can be taken as conveying an open-ended range of implicitly expressed meanings relating to matters in hand. Finally, we have universality - conversational implicatures tend to be universal, being rationally motivated rather than arbitrary (see e.g. Grice 1989; Levinson 2000; Huang 2011, 2014: 39-43, 2015, 2016, 2017a).

\subsection{Horn's bipartite neo-Gricean model}

Within the Gricean paradigm, the two most influential developments are the neo-Gricean pragmatic models advance by Horn and by Levinson.

Horn $(1984 ; 2004 ; 2012)$ put forward a bipartite model. In Horn's view, all of Grice's maxims (except the maxim of Quality) can be replaced with two fundamental and counterpoising principles: the Q[uantity]- and R[elation]-principles.

(42) Horn's Q- and R-principles

a. The Q-principle

Make your contribution sufficient;

Say as much as you can (modulo the R-principle).

b. The R-principle

Make your contribution necessary;

Say no more than you must (modulo the Q-principle).

In terms of information structure, Horn's Q-principle, which collects Grice's first sub-maxim of Quantity and his first two sub-maxims of Manner, is a lower-bounding pragmatic principle which may be (and characteristically is) exploited to engender upper-bounding conversational implicatures: a speaker, in saying '...p...., ceteris paribus conversationally implicates that (for all he or she knows) '... at most $p . .$. . The locus classicus here is those conversational implicatures that arise from a prototype Horn-scale. 
On the other hand, the counterbalancing R-principle, which subsumes Grice's second sub-maxim of Quantity, his maxim of Relation, and his last two sub-maxims of Manner, and which is based on Atlas \& Levinson's (1981) principle of informativeness, is an upper-bounding pragmatic law which may be (and systematically is) exploited to invite low-bounding conversational implicatures: a speaker, in saying '...p...., conversationally implicates that (for all he or she knows) '... more than $p . . .$. However, more recently Horn $(2007 ; 2012)$ has been of the view that the $\mathrm{R}$-principle is not in itself subsumable under Grice's co-operative principle, but under rationality.

\subsection{Levinson's trinitarian neo-Gricean pragmatic model}

Considering that the Horn model fails to draw a distinction between semantic and expression minimizations, Levinson (e.g. 1987, 2000) argued for a clear separation between pragmatic principles that govern an utterance's semantic or informational content and pragmatic principles that govern its surface linguistic form. Consequently, he proposed that the original Gricean programme (the maxim of Quality apart) be reduced to three neo-Gricean pragmatic principles: what he dubbed the Q[uantity]-, I[nformativeness]-, and M[anner]-principles. Each of the three principles has two sides: a speaker's maxim, which specifies what the principle enjoins a speaker to say and to implicate, and a recipient's corollary, which dictates what it allows the addressee to infer.

\section{(43) Levinson's Q-principle (simplified)}

Speaker: Do not say less than is required (bearing the I-principle in mind). Addressee: What is not said is not the case.

The basic idea of the metalinguistic Q-principle is that the use of an expression (especially a semantically weaker one) in a set of contrastive semantic alternates (such as a Q- or Horn-scale) Q-implicates the negation of the meaning/interpretation associated with the use of another expression (especially a semantically stronger one) in the same set. Seen the other way round, from the absence of a semantically or informationally stronger expression, we infer that the interpretation associated with the use of that expression does not hold. Hence, the Q-principle is essentially negative in nature.

Next, there is Levinson's I-principle.

(44) Levinson's I-principle (simplified)

Speaker: Do not say more than is required (bearing the Q-principle in mind). Addressee: What is generally said is stereotypically and specifically exemplified. 
Mirroring the effects of the Q-principle, the central tenet of the I-principle is that the use of a semantically general expression I-implicates a semantically more specific meaning/interpretation. More accurately, the conversational implicature engendered by the I-principle is one that accords best with the most stereotypical and explanatory expectation given our knowledge about the world.

Finally, we come to Levinson's M-principle.

(45) Levinson's M-principle (simplified)

Speaker: Do not use a marked expression without reason.

Addressee: What is said in a marked way conveys a marked message.

Unlike the Q- and I-principles, which operate primarily in terms of semantic informativeness, the metalinguistic $\mathrm{M}$-principle operates primarily in terms of a set of alternates that contrast in linguistic form. The fundamental axiom upon which this principle rests is that the use of a marked linguistic expression $\mathrm{M}$-implicates the negation of the meaning/interpretation associated with the use of an alternative, unmarked expression in the same set. Putting it another way, from the use of a marked linguistic expression, we infer that the stereotypical interpretation associated with the use of an alternative, unmarked linguistic expression does not obtain (see also Huang 2007, 2014: 44-66, 2017b, and some other articles in Huang 2017d).

\subsection{Unarticulated constituents in neo-Gricean pragmatics}

Given the Gricean co-operative principle (Be co-operative.) and Horn's R- (Make your contribution necessary; say no more than you must.) or Levinson's I-principle (Speaker: Do not say more than is required.), a speaker does not need to say more than is required. He or she can be less than fully explicit, and less than fully specific. In other words, he or she can utter a sentence whose semantic content, relative to a context, is less than fully propositional (i.e. a proposition that needs to be completed) or a sentence that amounts to a full, though minimal proposition, which is quite distinct from the one he or she wishes to communicate (i.e. a proposition that needs to be expanded). Furthermore, the speaker assumes and has good reason to believe that the addressee can compute the enriched version of the full, though minimal proposition which is semantically expressed by the uttered sentence.

On the other hand, when the addressee hears a sentence uttered by the speaker whose semantic content, tailored to a context, is either less than fully propositional or expresses a proposition that the speaker clearly does not m-intend to communicate, assuming that the speaker is still co-operative, he or she will use the $\mathrm{R}$ - or I-principle (Addressee: What is generally said is stereotypically and specifically exemplified.) automatically and unconsciously (or tacitly) to infer a semantically more specific proposition - the one the speaker m-intends to communicate. 
How can this be achieved? Let me start with type (i) propositions.

\section{Type (i) propositions}

Recall that type (i) propositions are incomplete and non-truth-evaluable, and need to be completed or saturated mandatorily. In other words, they contain what Recanati (2002) called B-type unarticulated constituents. Within neo-Gricean pragmatics, the pragmatic process of completion is achieved by the application of the R- or I-principle, relativized to a context. As an illustrating example, consider (8). Given the R- or I-principle, the speaker will utter the semantically general (8a) if he or she thinks that the addressee can contextually provide the unarticulated constituent, as in (8b). On the other hand, guided by the same pragmatic principle, the addressee will successfully retrieve from the context this phonologically null propositional material as $\mathrm{m}$-intended by the speaker, thus obtaining a semantically more specific interpretation in (8b). More or less the same analysis can be applied to, for instance, Examples (9-11).

\section{Type (ii) propositions}

As already mentioned, unlike in type (i) propositions, in type (ii) propositions, we have a full, though minimal proposition. In other words, this type of proposition contains what Recanati (2002) called A-type unarticulated constituents. There is no hidden, implicit, or covert semantic indexical, variable, or parameter in the syntax or at the logical form of the sentence that semantically expresses the proposition. Consequently, an unarticulated constituent in type (ii) proposition cannot be reduced to syntax or semantics. However, given that such a complete, though minimal proposition is not the appropriate one, that is, not the one that the speaker $\mathrm{m}$-intends to express in the relevant context, it still needs to be pragmatically expanded or enriched. Recanati (2002) called the pragmatic process of expansion free enrichment. It is free because it is purely and entirely pragmatic. It is typically optional and contextually driven or top-down.

Let me now consider some examples. ${ }^{14}$ When a speaker utters (12a), the linguistically overt meaning of the sentence alone can determine a full, though minimal proposition, namely, the proposition represented in (12b) without the bracketed pragmatically provided propositional ingredients. Furthermore, the proposition can be assigned a truth value, that is, it is true if and only if John hasn't washed his face since he was born. (Cf. John hasn't been to New Zealand.) But this is clearly not the suitable proposition, that is, the proposition that the speaker m-intends to communicate and the addressee will retrieve. As a consequence, the operation of the R- or I-principle is called for, engendering contextually the pragmatically

14. Space limitation does not allow me to go over all the examples listed in (6-34). 
augmented proposition in (12b) - the one that the speaker wants to convey and the addressee will recover.

The sentence in (6a) contains the meteorological predicate rain. As already mentioned above, sometimes, such a predicate needs to be made location-specific. When it rains (at a given time), it usually rains at a particular place, typically where the speaker is. In other words, the proposition semantically expressed by the utterance of (6a) has an optional unarticulated constituent. When the information about the location of a particular event of raining is relevant to the accepted purposes of a particular conversation, it cannot be left out of the picture. Putting it slightly differently, the contextual provision of the unarticulated constituent in (6a) is pragmatically motivated and warranted. On the authority of the R- or I-principle, a specific place will then be implicated, tailored to a context, as in (6b). Notice that unlike in the Stanley-Marti hidden indexical or covert variable analysis, within our neo-Gricean account, (6a) does not have multiple logical forms. Instead, it only has a single logical form, namely, the one without the hidden indexical or covert variable for location. It is only if and when pragmatically licensed that can the location of raining be supplied, relative to a context. ${ }^{15}$ The same story can be told of (7). When a speaker says (7a), he or she does not normally mean that it is summer everywhere on the Earth. Rather, he or she must m-intend some location as part of what he or she means. By the R- or I-principle, we get the meaning that is more contextually specific than the literal meaning, namely, the pragmatically enriched proposition in (7b). ${ }^{16}$

15. For the interpretation of an existentially closed sentence like (36) and (37), somewhat following Perry (1993; 1998), Recanati (2002) made an appeal to the notion of metaphysical unarticulated constituents, namely, the view that it is a metaphysical fact that every raining event takes place somewhere. This view seems to be somewhat shared by Cappelen \& Lepore (2017: 199), who argued that '([6]) provides a particularly clear illustration of how nonsemantic (and more generally, nonlinguistic) facts about the subject matter of our sentences determine communicated content.' The same analysis applies to a sentence such as Nina danced last night (Taylor 2001).

16. Needless to say, the same analysis can also be applied to (16), where an unarticulated compare class needs to be made explicit. Notice that such a proto-Gricean pragmatic account can go back at least as far as the early 1970s (see e.g. Katz 1972: 449 and Walker 1975: 156-157). But following an analysis by Heim \& Kratzer (1998: 70-72) of the relative (or noninsective in their terminology) adjective small, Jo-wang Lin proposed an alternative formal semantic account to me. In this analysis, the meaning of tall can be listed as follows, where $\mathrm{f}$ can be reanalysed as a hidden indexical. This has the consequence that the vagueness and context dependency of tall is captured as part of its lexical entry or lexical semantics.

$$
\left.[\text { tall }]=\lambda \mathrm{xf}_{<\mathrm{e}, \mathrm{t}\rangle} .[\lambda \mathrm{x} . \mathrm{x} \text { is above the average height for the entities in }\{\mathrm{y}: \mathrm{f}(\mathrm{y})=\mathrm{T}\}]\right]
$$

I am not saying that vagueness and context dependency cannot be encoded in the lexicon of these adjectives. What I am saying is that if they are incorporated into the lexicon, then the analysis is not a purely formal semantic one but a semantico-pragmatic one. Another alternative semantic 
Next, the proposition determined by the linguistic meaning of (26a) is trivially true, given that everyone has a brain. In addition to (26), we have (46-48).

(46) a. The little girl has a temperature.

b. The little girl has a [high] temperature.

(47) a. Please have a heart for animals this Valentine's Day!

b. Please have a [kind] heart for animals this Valentine's Day!

(48) a. Clinton made a lot of noise and had a very big impact. He has the shoulders. If he comes, the world is interested, and it brings attention to Lesotho. When I climb on the foothills of Clinton, perhaps people will notice more.

(FT Magazine 19/20 August 2006)

b. Clinton made a lot of noise and had a very big impact. He has the [strong] shoulders. If he comes, the world is interested, and it brings attention to Lesotho. When I climb on the foothills of Clinton, perhaps people will notice more. ${ }^{17}$

More or less the same is true of the proposition of the distance-time sentence in (27a). Needless to say, doing anything takes time. In addition to (27), there are (49) and (50).

(49) a. The Buddhist temple is a distance away from the railway station.

b. The Buddhist temple is a [long] distance away from the railway station.

(50) a. You need money to buy a house in Hong Kong.

b. You need [a lot of] money to buy a house in Hong Kong.

account can be found in what is known as non-indexical contextualism in the philosophy of language. Despite its name, non-indexical contexutalism falls largely in the (semantic) minimalist camp. In this view, context-sensitivity is not caused by the semantic content or truth condition of a sentence but by a variation in its circumstances of evaluation. In other words, a sentence like (16) is context-sensitive, not because it expresses different propositions in different contexts, but because the truth or falsity of its occurrences depends on the circumstances in which it is evaluated. A circumstance of evaluation has two parameters: (i) one for the possible world(s) and (ii) one for 'counts-as'. The 'counts-as' parameter is a function from properties (such as tallness) to intensions. It is so-called because 'it fixes what things have to be like in order to count as having the property of tallness (or any other property) at a circumstance of evaluation' (MacFarlane 2007: 246). Thus, according to this analysis, the different utterances of (16) on different occasions of use may have different truth values because they have different circumstances of evaluation, even if they are situated at or reside in the same possible world, and express the same proposition (see also Huang 2014: 309-311, 2017b: 71-72).

17. Cross-linguistically, a noun denoting a human body part is commonly used in this type of proposition. For instance, examples similar to (26a) and (47a) are also found in Arabic, Chinese, and Modern Greek. Other human body part-denoting nouns such as tou (head), lian (face), and nai/xiong 'breast' in Chinese are also frequently used in this way. 
Like a tautology (e.g. War is war.), sentences like those in the (a) of (26), (27), and (46-50) are superficially uninformative. Confronted with the blatant infringement of Grice's maxim of Quantity, the addressee assumes that the speaker is actually co-operative, and has to work out why he or she has used such apparently uninformative sentences. The only way to do it is to interpret them as highly informative. Given the R- or I-principle, something more than the literal meanings linguistically determined by these sentences, which is $\mathrm{m}$-intended by the speaker, is computed, thus the pragmatically strengthened propositions in the (b) of these sentences (see also Huang 2017c).

On the other hand, the propositions linguistically expressed by the uttering of the sentences in (28) above and (51-53) below are patently false, because a human being is not immortal, Stalin was a human being, there are TV stations that air programmes twenty-four hours a day and 365 days a year, and Mary does not eat, for example, rocks.

(51) a. Stalin was not a human being.

b. Stalin did not [possess the basic qualities as] a human being. ${ }^{18}$

(52) a. There is nothing to watch on TV tonight.

b. There is nothing [I/the speaker consider/considers worth] watching on TV tonight.

(53) a. Mary eats everything.

b. Mary eats everything [that is edible for human beings]. ${ }^{19}$

In all these cases, the speaker has clearly and openly flouted Grice's maxim of Quality. However, in order to preserve the assumption of co-operation, the addressee must assume that the speaker is trying to convey something rather different from what he or she has literally said in the (a) of (28) and (51-53). This gives rise to the expansion of the propositional content of these sentences in the form of the $\mathrm{R}$ - or I-principle, as indicated in the (b) of (28) and (51-53).

18. I am grateful to the anonymous referee for this better interpretation. Interestingly enough, in the process of revising this article, the following attested example came to my attention.

(i) Eric Trump, son of President Trump, said of Democrats, 'I've never seen hatred like this. To me, they're not even people. It's so, so sad.'

(USA Today 7 June 2017)

19. The anonymous referee pointed out that the pragmatic enrichment for (53a) is 'Mary is not picky with food' rather than (53b). In fact, (53) may have two or more pragmatic enrichments: (53b) is a pre-semantic conversational implicature, contributing to the truth-conditional, propositional content of (53a), and the one pointed out by the referee may be one of the post-semantic conversational implicatures. 
(30) is a typical case of bridging-cross reference. In bridging-cross reference, the anaphoric expression is used to establish a link of association with some preceding linguistic expression (that is, its 'antecedent') in the same sentence or discourse via the addition of certain background assumptions. What is tacitly 'bridged' is typically the information that is not structurally or linguistically retrievable from either the sentence or discourse but pragmatically R- or I-enriched. This R- or I-enriched background information results in the pragmatically expanded proposition in (30b) (see also Huang 2000: 249-253, 2014).

We finally move to deferred reference. In addition to (31), we have (54-56).

(54) a. I'm in the phonebook.

b. [My/the speaker's address and phone number] are in the phonebook.

(55) (A waitress said to another waitress in a restaurant)

a. The ham sandwich has left without paying.

b. [The customer who has ordered] the ham sandwich has left without paying.

(56) a. The trams are on strike.

b. [The drivers of] the trams are on strike.

In deferred or transferred reference, a referring expression is metonymically used to stand for an entity that is somewhat related to but not denoted by the conventional, linguistic meaning of that expression. In Huang (2014: 252-259), I outlined a neo-Gricean pragmatic analysis of deferred reference, incorporating Kripke's (1977; 1980) semantic versus speaker reference distinction. According to this analysis, in transferred reference, the trigger is the semantic referent, and the target, namely, the $\mathrm{m}$-intended shifted referent is the speaker's referent. The pragmatic process involved is once again the R- or I-enrichment. Thus, in (31), for example, given that the encoded meaning/referent (Dickens) is clearly not the meaning/referent that is $\mathrm{m}$-intended to be communicated by the speaker in the uttering of (31a) nor the meaning/referent that will actually be grasped by the addressee in hearing (31a), a meaning/referent shift will take place. In terms of Kripke's distinction, Dickens is the semantic referent and the novels written by him are the speaker referent. On the application of the R- or I-principle, the semantic referent is pragmatically adjusted to the speaker referent. Essentially the same analysis can be extended to (54-56).

Note next that a sentence can sometimes be ambiguous between a literary and a transferred referential reading.

(57) Yeats is still widely read.

(Nunberg 1995)

(57) can be understood either in the manner of the literal reference, as in (58a) or in the manner of the transferred reference, as in (58b). 
(58) a. Yeats is still widely read, though he has been dead for more than fifty years.

b. Yeats is still widely read, even though most of it is out of print.

Given the above analysis, under the literal interpretation, the semantic and the speaker referents converge on one and the same entity, as in (58a). There is no application of the R- or I-principle. On the other hand, in the case of the transferred reference, the literal referent, the Irish poet and dramatist Yeats is the semantic referent and the m-intended, deferred referent, his work, is the speaker referent. The pragmatic shift from the semantic referent to the speaker referent is due to the working of the R- or I-principle.

\section{Pragmatic enrichment of unarticulated constituents: Explicature, the pragmatically enriched said, conversational impliciture or conversational implicature?}

In the last section, I presented a neo-Gricean pragmatic analysis of unarticulated constituents. In this section, I consider the question of what the pragmatic enrichment that is required to recover the semantic content of unarticulated constituents is.

Currently, within pragmatics and the philosophy of language, two approaches can be identified: (i) the non-conversational-implicature approach and (ii) the conversational implicature approach. Within the first camp, three analyses are of particular interest. First, in relevance theory, pragmatic enrichment of this kind is analysed as explicature - an inferential development of one of the linguistically-given incomplete conceptual representations or logical forms of a sentence uttered (e.g. Sperber \& Wilson 1995; Carston 2002). Defined thus, an explicature is a pragmatically inferred, explicitly communicated component of the Gricean notion of what is said (though what is said is abandoned in relevance theory) (see e.g. Huang 2012 for a comparison between relevance theory and neo-Gricean pragmatic theory). Second, somewhat similar to the relevance-theoretic view is the position taken by Recanati (e.g. 2004, 2010), according to which, the pragmatic enrichment under discussion is part of the pragmatically enriched said. Finally, a third approach is due to Bach (e.g. 1994, 2012). In Bach's view, certain communicative content does not need to be recognized as either part of what is said or part of what is conversationally implicated. Rather, it constitutes a middle ground between what is said and what is conversationally implicated. Bach dubbed this middle level of speaker meaning (conversational) impliciture - impliciture for short.

On the other hand, within the neo-Gricean pragmatic framework, Levinson (2000: 195-196) and Huang (e.g. 2005, 2007, 2013d, 2014, 2017a) are of the view that the pragmatic enrichment under consideration is not an explicature; the 
pragmatically enriched said; or an impliciture. Rather, it is the same beast as a neoGricean conversational implicature. ${ }^{20}$ In my view (e.g. Huang 2005, 2007, 2013b, c, d, 2014), the reason why it is a conversational implicature is fivefold. First, like a conversational implicature, so-called explicature/the pragmatically enriched said/ impliciture is also a meaning or proposition expressed implicitly by a speaker in the utterance of a sentence which is meant without being said in its strict sense. Second, it is engendered largely by the same Gricean pragmatic reasoning that yields a conversational implicature. That is to say, it is derived from the saying of what is said via Grice's co-operative principle and its subordinate maxims of conversation. Third, it is subject to the same set of hallmarks proposed by Grice for a conversational implicature. For example, so-called explicature/the pragmatically enriched said/impliciture can be defeated, as in (59c); it can be reinforced, as in (60c), and it tends to be universal, to mention but three.

(59) a. John and Sue are married.

b. John and Sue are married [to each other].

c. John and Sue are married, but not to each other.

(60) a. John has a heart for refugees.

b. John has a [kind] heart for refugees.

c. John has a heart, I mean, a kind heart, for refugees.

Fourth, currently there is no reliable test either in theoretical or experimental pragmatics that can be utilised to distinguish alleged explicature/the pragmatically enriched said/impliciture from conversational implicature on a principled basis. Recanati (1993) claimed that the distinction between explicature/the pragmatically augmented said/impliciture and conversational implicature can be delineated on an intuitive basis. This is captured in his availability principle in (61).

(61) Recanati's (1993) availability principle (my rendering)

In deciding whether a pragmatically determined aspect of utterance meaning is explicature/part of what is said/impliciture, we should always try to preserve our pre-theoretical intuition on the matter.

What the availability principle basically says is this: explicature/the pragmatically enriched aspect of what is said/impliciture is consciously available to the speaker and the addressee. However, as we have already seen in relation to (6),

20. See my (earlier) neo-Gricean and revised neo-Gricean pragmatic analyses of anaphora in Huang (1991; 1994/2007; 2000; 2004; 2007; 2013b, c, d, and 2014), which in effect argue that the pragmatic enrichment involved in the determination of anaphoric reference is a neo-Gricean, pre-semantic conversational implicature. 
people's pre-theoretical intuitions tend to be different. For example, Taylor (2001) took (6) to be location-obligatory (the 'subatomic structure' of rain has an obligatory argument place for location). For both Recanati (2002) and Marti (2006), (6) is location-optional, but the crucial difference between them is that while Recanati considered rain a zero-predicate (that is, it does not carry an implicit argument slot for location) and the location is supplied only when pragmatically mandated, Marti claimed that there is an implicit adjunct in the lexical semantics of rain. Finally, Cappelen \& Lepore (2007) were of the view that (6) is location-neutral. All this is a clear indication that people's pre-theoretical intuition may not be very reliable at least in some cases. Therefore, (61) has to be taken with great caution.

The second test put forward by Recanati for drawing the division between explicature/the pragmatically enriched said/impliciture and conversational implicature is the scope principle, essentially following an earlier proposal by Cohen (1971).

(62) The Cohen-Recanati scope principle (my rendering)

A pragmatically determined aspect of meaning is explicature/part of what is said/impliciture, (and, therefore, not a conversational implicature) if - and, perhaps, only if - it falls within the scope of logical operators.

There is a serious problem attaching to the Cohen-Recanati scope test. As is aware by Recanati himself, the problem is concerned with metalinguistic negation. By metalinguistic negation is meant a device for rejecting a previous utterance on any grounds whatever including its morphosyntactic form, its phonetic realization, its style or register, and/or the conversational implicatures it potentially engenders.

(63) a. The water in the river isn't cold, it's downright freezing.

b. They don't speak [seltic], they speak [keltic].

c. I don't use elevators, I use lifts.

Of these examples, (63a) is of particular relevance to our discussion here. But before proceeding to discuss it, let me first consider (64). The uttering of (64) gives rise to the $\mathrm{Q}_{\text {-scalar }}$ implicature in (65).

(64) <freezing, cold, cool>

The water in the river is cold.

(65) The water in the river is not freezing.

Notice that when (64) is negated descriptively, as in (66), the original $\mathrm{Q}_{\text {-scalar }}$ implicature is preserved. In other words, it falls within the scope of negation. Given the Cohen-Recanati scope test, the pragmatic enrichment here cannot be a conversational implicature. Rather, it is taken to be an explicature/a pragmatic constituent of what is said/an impliciture. 
(66) The water in the river isn't cold, it's cool.

Returning next to (63a), where (64) is negated in a metalinguistic way. In (63a), the speaker does not deny that the water is cold, because that is entailed by what the speaker asserts, namely that the water is downright freezing. What is rejected here is nothing but the very same $\mathrm{Q}_{\text {-scalar }}$ implicature. Put another way, in (63a) the conversational implicature falls outside the scope of negation. By virtue of the Cohen-Recanati scope criterion, the pragmatic enrichment here has to be considered as a genuine conversational implicature. The contrast shown by (64) and (63a) gives rise to a puzzle, namely, why the same $\mathrm{Q}_{\text {-scalar }}$ implicature may or may not fall within the scope of negation, hence may or may be a genuine conversational implicature (see also Levinson 2000). From all this, we can conclude that explicature/the pragmatically enriched said/impliciture may not be distinguished from conversational implicature on a principled theoretical basis.

Finally, given the meta-theoretical principle known as 'Occam's razor, other things being equal, the conversational implicature analysis is theoretically and methodologically preferable, because it postulates fewer theoretical categories than the explicature/the pragmatically enriched said/impliciture alternatives. If neo-Gricean conversational implicature can intrude onto the truth-conditional, propositional content of an utterance, then a problem known as Grice's circle arises, namely, how what is conversationally implicated can be defined in contrast to, and calculated on the basis of what is said, given that what is said seems to both determine and to be determined by what is conversationally implicated. Levinson's (2000) proposal was that we should reject the 'received' view of the semantics-pragmatics interface, namely, the view that the output of semantics is the input to pragmatics, and allow conversational implicatures to play a systematic role in pre-semantics, that is, to help determine the truth-conditional, propositional content of an utterance (e.g. Levinson 2000; Huang 2005, 2007, 2013b, c, d, 2014, 2017a). Putting it slightly differently, in order to avoid Grice's circle, we need dual pragmatics, that is, both pre- and post-semantic pragmatics. The pragmatic enrichment of unarticulated constituents is therefore a neo-Gricean, pre-semantic conversational implicature. ${ }^{21}$

21. Even if the dispute were entirely of a terminological rather than a substantive nature, the force of my argument remains, given the fact that having fewer technical terms is better than having more. 


\section{Conclusions}

In this article, I have provided a neo-Gricean pragmatic analysis of unarticulated constituents. I have defended the neo-Gricean position that the pragmatic enrichment of unarticulated constituents is nothing but a neo-Gricean, pre-semantic conversational implicature. I have also commented on the alternative syntactico-semantic analysis known as the hidden indexical analysis.

In response to the three issues raised at the beginning of this essay, my conclusions are:

i. There are genuine unarticulated constituents. According to a broad definition, unarticulated constituents can be divided into two types: syntactico-semantic ones (phonologically unrealized but linguistically/syntactically or semantically called for/mandated), as in type (i) propositions, and pragmatic ones (neither phonologically present nor linguistically/syntactically or semantically triggered), as in type (ii) propositions. By contrast, given a narrow definition, there are only pragmatic unarticulated constituents, as in type (ii) propositions.

ii. The semantic content of unarticulated constituents is pragmatically recovered via the $\mathrm{R}$ - or I-principle in neo-Gricean pragmatics.

iii. The pragmatic enrichment involved in the recovery of the semantic content of unarticulated constituents is not an explicature, part of the pragmatically enriched said, or impliciture but a neo-Gricean, pre-semantic conversational implicature.

\section{Acknowledgements}

Part of the material contained in, and earlier versions of, this article were presented at a number of international conferences including the 1st Pragmatics Conference of the Americas (University of South Carolina 2012), the 19th Congress of Linguists (Université de Genève 2013), (as an invited, keynote speech) the 4th International Cognitive Semantics Conference (Hunan University 2013), the Linguistics Association of Great Britain Annual Meeting (Oxford University 2014), (as an invited, keynote speech) Pragmasophia I - the 1st International Conference in Pragmatics and Philosophy (Università degli Studi di Palermo 2016), and the International Workshop on Implicatures or Domain Restriction/Widening: Theoretical and Experimental Approaches (Research Institute for Linguistics, Hungarian Academy of Sciences and Pázmány Péter Catholic University 2017). In addition, they were also given as invited lectures at a number of research colloquia/seminars held in the University of Auckland, Harvard University, the University of Hawai'i at Mānoa, Nanyang Technological University, La Trobe University, and Tianjing University. I have benefited from the comments received on all these occasions. I particularly wish to thank Kent Bach for his insightful comments. This does not necessarily mean that he agrees with my arguments and analyses developed in the paper. I am grateful to Robyn Carston for answering my enquiries. To Jo-wang Lin, editor-in-chief of this journal, I own a 
special debt of gratitude. His comments on and criticisms of my comments on and criticisms of the Stanley-type formal syntactico-semantic account known as the hidden indexical analysis has pushed me to think more carefully and deeply about this aspect of my article. After much heated e-mail exchange, we have decided to agree to disagree and let the readership form their own views. My thanks go to an anonymous referee of this journal for his or her useful comments. In addition, I would like to extend a note of thanks to Chiu-yu Tseng and Chih-Chen Jane Tang for commissioning me to submit an article to this journal. Finally, I dedicate this paper to the memory of John Davey, formerly the Consultant Editor of Linguistics at Oxford University Press. Since 2000, I have published five books with the Press. I must record here my gratitude to him for his interest in my research and the encouragement he had given me over the years. Needless to say, the usual absolution of any responsibility for remaining errors and shortcomings is in effect here.

\section{Abbreviations}

$\begin{array}{ll}{[\text { at } t]} & \text { time/tense } \\ \text { CNSWR } & \begin{array}{l}\text { constituency in a node of a structure without representation } \\ \text { CWR }\end{array} \\ \text { constituency without representation } \\ \text { Det } & \text { determiner } \\ \text { EC } & \text { empty category } \\ \text { F } & \text { flouting } \\ \text { I- } & \text { informativeness- } \\ \text { [in } l] & \text { location } \\ \text { M- } & \text { manner- } \\ {[m]} & \text { manner } \\ \text { N } & \text { noun } \\ \text {-NN } & \text { [non][natural] } \\ \text { NP } & \text { noun phrase } \\ \text { O } & \text { observing } \\ \text { PFV } & \text { perfective } \\ \text { Q- } & \text { quantity- } \\ \text { R- } & \text { relation- } \\ \text { S } & \text { subject } \\ \text { V } & \text { verb } \\ \text { VP } & \text { verbal phrase } \\ \end{array}$

\section{References}

Atlas, Jay D. \& Levinson, Stephen C. 1981. It-clefts, informativeness and logical form: Radical pragmatics. In Cole, Peter (ed.), Radical pragmatics, 1-61. New York: Academic Press.

Bach, Kent. 1994. Conversational impliciture. Mind \& Language 9(2). 124-162.

doi: 10.1111/j.1468-0017.1994.tboo22o.x 
Bach, Kent. 2000. Quantification, qualification and context: A reply to Stanley and Szabó. Mind \& Language 15(2-3). 262-283. doi:10.1111/1468-0017.00131

Bach, Kent. 2004. Pragmatics and the philosophy of language. In Horn, Laurence R. \& Ward, Gregory (eds.), The handbook of pragmatics, 463-487. Oxford: Blackwell.

Bach, Kent. 2012. Context dependence. In Garcia-Carpintero, Manuel \& Kolbel, Max (eds.), The Continuum companion to the philosophy of language, 153-184. London: Continuum.

Bezuidenhout, Anne. 2017. Contextualism and semantic minimalism. In Huang, Yan (ed.), The Oxford handbook of pragmatics, 21-46. Oxford: Oxford University Press.

Borg, Emma. 2005. Saying what you mean: Unarticulated constituents and communication. In Elugardo, Reinaldo \& Stainton, Robert J. (eds.), Ellipsis and nonsentential speech, 237-262. Dordrecht: Springer. doi:10.1007/1-4020-2301-4_13

Cappelen, Herman \& Lepore, Ernie. 2007. The myth of unarticulated constituents. In O'Rourke, Michael \& Washington, Corey (eds.), Situating semantics: Essays on the philosophy of John Perry, 199-214. Cambridge: The MIT Press.

Carston, Robyn. 2002. Thoughts and utterances: The pragmatics of explicit communication. Oxford: Blackwell. doi:10.1002/9780470754603

Carston, Robyn. 2010. Explicit communication and 'free' pragmatic enrichment. In Soria, Belén \& Romero, Esther (eds.), Explicit communication: Robyn Carston's pragmatics (Palgrave Studies in Pragmatics, Language and Cognition), 217-285. Basingstoke: Palgrave Macmillan.

Chomsky, Noam. 1995. The minimalist program. Cambridge: The MIT Press.

Cohen, L. Jonathan. 1971. Some remarks on Grice's views about the logical particles of natural language. In Bar-Hillel, Yehoshua (ed.), Pragmatics of natural languages, 50-68. Dordrecht: D. Reidel. doi:10.1007/978-94-010-1713-8_3

Crimmins, Mark. 1992. Talk about beliefs. Cambridge: The MIT Press.

Grice, H. P. 1975. Logic and conversation. In Cole, Peter \& Morgan, Jerry L. (eds.), Syntax and semantics 3: Speech acts, 41-58. London: Academic Press.

Grice, H. P. 1989. Studies in the way of words. Cambridge: Harvard University Press.

Hall, Alison. 2008. Free enrichment or hidden indexicals? Mind \& Language 23(4). 426-456. doi: 10.1111/j.1468-0017.2008.00350.x

Heim, Irene \& Kratzer, Angelika. 1998. Semantics in generative grammar. Oxford: Blackwell.

Horn, Laurence R. 1984. Toward a new taxonomy for pragmatic inference: Q-based and R-based implicature. In Schiffrin, Deborah (ed.), Meaning, form, and use in context: Linguistic applications, 11-42. Washington, DC: Georgetown University Press.

Horn, Laurence R. 2004. Implicature. In Horn, Laurence R. \& Ward, Gregory (eds.), The handbook of pragmatics, 3-28. Oxford: Blackwell.

Horn, Laurence R. 2007. Neo-Gricean pragmatics: A Manichaean manifesto. In Burton-Roberts, Noel (ed.), Pragmatics, 158-183. Basingstoke: Palgrave Macmillan.

Horn, Laurence R. 2012. Implying and inferring. In Allan, Keith \& Jaszczolt, Kasia M. (eds.), The Cambridge handbook of pragmatics, 69-86. Cambridge: Cambridge University Press. doi: $10.1017 / C B O 9781139022453.005$

Huang, Yan. 1991. A neo-Gricean pragmatic theory of anaphora. Journal of Linguistics 27(2). 301-335. doi:10.1017/So022226700012706

Huang, Yan. 1992a. Against Chomsky's typology of empty categories. Journal of Pragmatics 17(1). 1-29. doi:10.1016/0378-2166(92)90026-8

Huang, Yan. 1992b. Hanyu de kongfanchou [Empty categories in Chinese]. Zhongguo Yuwen [Studies of the Chinese Language] 1992(5). 384-393. 
Huang, Yan. 1994/2007. The syntax and pragmatics of anaphora: A study with special reference to Chinese (Cambridge Studies in Linguistics 70). Cambridge: Cambridge University Press. doi: $10.1017 / C B O 9780511554292$

Huang, Yan. 2000. Anaphora: A cross-linguistic study (Oxford Studies in Typology and Linguistic Theory). Oxford: Oxford University Press.

Huang, Yan. 2004. Anaphora and the pragmatics-syntax interface. In Horn, Laurence R. \& Ward, Gregory (eds.), The handbook of pragmatics, 288-314. Oxford: Blackwell.

Huang, Yan. 2005. Pragmatic intrusion into what is said: Explicature, pragmatically enriched 'said', implicIture or implicAture? (Paper presented at the 27th Annual Meeting of the German Linguistic Society, Cologne, 23-26 February 2005.)

Huang, Yan. 2007. Pragmatics (Oxford Textbooks in Linguistics). Oxford: Oxford University Press.

Huang, Yan. 2011. Types of inference: Entailment, presupposition, and implicature. In Bublitz, Wolfram \& Norrick, Neal R. (eds.), Foundations of pragmatics (Handbook of Pragmatics 1), 397-422. Berlin: De Gruyter Mouton. doi:10.1515/9783110214260.397

Huang, Yan. 2012. Relevance and neo-Gricean pragmatic principles. In Schmid, Hans-Jörg (ed.), Cognitive pragmatics (Handbook of Pragmatics 4), 25-46. Berlin: De Gruyter Mouton. doi: $10.1515 / 9783110214215.25$

Huang, Yan. 2013a. Micro- and macro-pragmatics: Remapping their terrains. International Review of Pragmatics 5(1). 129-162. doi:10.1163/18773109-13050106

Huang, Yan. 2013b. Bayesian probabilistic model of discourse anaphoric comprehension, linguistic typology, and neo-Gricean pragmatics. Theoretical Linguistics 39(1-2). 95-108.

Huang, Yan. 2013c. De se attitude/belief ascription and neo-Gricean truth-conditional pragmatics: Logophoric expressions in West African languages and long-distance reflexives in East, South, and Southeast Asian languages. In Feit, Neil \& Capone, Alessandro (eds.), Attitude de se: Linguistics, epistemology, metaphysics, 185-209. Stanford: CSLI Publications.

Huang, Yan. 2013d. Logophoricity and neo-Gricean truth-conditional pragmatics. In Capone, Alessandro \& Lo Piparo, Franco \& Carapezza, Marco (eds.), Perspectives on linguistic pragmatics (Perspectives in Pragmatics, Philosophy \& Psychology 2), 217-241. New York: Springer. doi:10.1007/978-3-319-01014-4_8

Huang, Yan. 2014. Pragmatics (Oxford Textbooks in Linguistics). 2nd edn. New York: Oxford University Press.

Huang, Yan. 2015. Neo-Gricean pragmatic theory of conversational implicature. In Heine, Bernd \& Narrog, Heiko (eds.), The Oxford handbook of linguistic analysis, 615-639. 2nd edn. New York: Oxford University Press.

Huang, Yan. 2016. Pragmatics: Language use in context. In Allan, Keith (ed.), The Routledge handbook of linguistics, 205-220. Oxford: Routledge.

Huang, Yan. 2017a. Implicature. In Huang, Yan (ed.), The Oxford handbook of pragmatics, 155179. Oxford: Oxford University Press.

Huang, Yan. 2017b. Neo-Gricean pragmatics. In Huang, Yan (ed.), The Oxford handbook of pragmatics, 47-78. Oxford: Oxford University Press.

Huang, Yan. 2017c. Implicitness in the lexis: Lexical narrowing and neo-Gricean pragmatics. In Cap, Piotr \& Dynel, Marta (eds.), Implicitness: From lexis to discourse (Pragmatics \& Beyond New Series 276), 67-94. Amsterdam: John Benjamins. doi:10.1075/pbns.276.04hua

Huang, Yan (ed.). 2017d. The Oxford handbook of pragmatics. Oxford: Oxford University Press. Katz, Jerrold J. 1972. Semantic theory. New York: Harper \& Row. 
King, Jeffrey C. 2007. The nature and structure of content. Oxford: Oxford University Press. doi:10.1093/acprof:oso/9780199226061.001.0001

King, Jeffrey C. \& Stanley, Jason. 2005. Semantics, pragmatics, and the role of semantic content. In Szabó, Zoltán Gendler (ed.), Semantics versus pragmatics, 111-164. Oxford: Clarendon Press. doi: 10.1093/acprof:0so/9780199251520.003.0005

Kripke, Saul. 1977. Speaker's reference and semantic reference. Midwest Studies in Philosophy 2(1). 255-276. doi:10.1111/j.1475-4975.1977.tbooo45.x

Kripke, Saul A. 1980. Naming and necessity. Cambridge: Harvard University Press.

Levinson, Stephen C. 1987. Pragmatics and the grammar of anaphora: A partial pragmatic reduction of Binding and Control phenomena. Journal of Linguistics 23(1987). 379-434. doi: $10.1017 /$ Soo 22226700011324

Levinson, Stephen C. 2000. Presumptive meanings: The theory of generalized conversational implicature. Cambridge: The MIT Press.

MacFarlane, John. 2007. Semantic minimalism and nonindexical contextualism. In Preyer, Gerhard \& Peter, Georg (eds.), Context-sensitivity and semantic minimalism: New essays on semantics and pragmatics, 240-250. Oxford: Oxford University Press.

Marti, Luisa. 2006. Unarticulated constituents revisited. Linguistics and Philosophy 29(2). 135-166. doi: $10.1007 /$ s10988-005-4740-4

Nunberg, Geoffrey. 1995. Transfers of meaning. Journal of Semantics 12(2). 109-132. doi:10.1093/jos/12.2.109

Partee, Barbara H. 1989. Binding implicit variables in quantified contexts. In Wiltshire, Caroline \& Graczyk, Randolph \& Music, Bradley (eds.), CLS 25: Papers from the 25th Annual Regional Meeting of the Chicago Linguistic Society, 342-365. Chicago: Chicago Linguistic Society.

Perry, John. 1986. Thought without representation. Proceedings of the Aristotelian Society, supplementary volumes 60. 137-151. doi:10.1093/aristoteliansupp/60.1.137

Perry, John. 1993. The problem of the essential indexical: And other essays. Oxford: Oxford University Press.

Perry, John. 1998. Indexicals, contexts, and unarticulated constituents. In Aliseda-Llera, Atocha \& Van Glabbeek, Rob \& Westerståhl, Dag (eds.), Computing natural language, 1-11. Stanford: CSLI Publications.

Recanati, François. 1993. Direct reference: From language to thought. Oxford. Blackwell.

Recanati, François. 2002. Unarticulated constituents. Linguistics and Philosophy 25(3). 299-345. doi: 10.1023/A:1015267930510

Recanati, François. 2004. Literal meaning. Cambridge: Cambridge University Press.

Recanati, François. 2007. It is raining (somewhere). Linguistics and Philosophy 30(1). 123-146. doi: 10.1007/s10988-006-9007-1

Recanati, François. 2010. Truth-conditional pragmatics. Oxford: Oxford University Press. doi:10.1093/acprof:oso/9780199226993.001.0001

Saul, Jennifer M. 2002. What is said and psychological reality: Grice's project and relevance theorists' criticisms. Linguistics and Philosophy 25. 347-372. doi:10.1023/A:1015221313887

Schiffer, Stephen. 1977. Naming and knowing. Midwest Studies in Philosophy 2(1). 28-41. doi: 10.1111/j.1475-4975.1977.tbooo26.x

Sennet, Adam. 2011. Unarticulated constituents and propositional structure. Mind \& Language 26(4). 412-435. doi:10.1111/j.1468-0017.2011.01423.x

Sperber, Dan \& Wilson, Deirdre. 1995. Relevance: Communication and cognition. 2nd edn. Oxford: Blackwell. 
Stainton, Robert. 2006. Words and thoughts: Subsentences, ellipsis, and the philosophy of language. Oxford: Oxford University Press. doi:10.1093/acprof:oso/9780199250387.001.0001

Stanley, Jason. 2000. Context and logical form. Linguistics and Philosophy 23(4). 391-434. doi:10.1023/A:1005599312747

Stanley, Jason. 2002. Making it articulated. Mind \& Language 17(1-2). 149-168. doi: 10.1111/1468-0017.00193

Stanley, Jason. 2005. Semantics in context. In Preyer, Gerhard \& Peter, Georg (eds.), Contextualism in philosophy: Knowledge, meaning, and truth, 221-254. Oxford: Clarendon Press.

Stanley, Jason \& Szabó, Zoltán Gendler. 2000a. On quantifier domain restriction. Mind \& Language 15(2-3). 219-261. doi:10.1111/1468-0017.00130

Stanley, Jason \& Szabó, Zoltán Gendler. 2000b. Reply to Bach and Neale. Mind \& Language 15(2-3). 295-298. doi:10.1111/1468-0017.00133

Taylor, Kenneth A. 2001. Sex, breakfast, and descriptus interruptus. Synthese 128(1-2). 45-61. doi: 10.1023/A:1010349621943

Vicente, Begoña \& Groefsema, Marjolein. 2013. Something out of nothing? Rethinking unarticulated constituents. Journal of Pragmatics 47(1). 108-127. doi:10.1016/j.pragma.2012.12.009

Walker, Ralph C. S. 1975. Conversational implicatures. In Blackburn, Simon (ed.), Meaning, reference, and necessity: New studies in semantics, 133-181. Cambridge: Cambridge University Press.

Westerståhl, Dag. 1985. Determiners and context sets. In van Benthem, Johan \& A. ter Meulen, Alice (eds.), Generalized quantifiers in natural languages, 45-72. Dordrecht: Foris. doi: $10.1515 / 9783110867909.45$

\section{Author's address}

Yan Huang

School of Cultures, Languages and Linguistics

Faculty of Arts

The University of Auckland

Private Bag 92019, Auckland 1142

New Zealand

yan.huang@auckland.ac.nz

\section{Publication history}

Date received: 23 April 2016

Date received: 18 July 2017 